TITLE:

\title{
Niobium powder synthesized by calciothermic reduction of niobium hydroxide for use in capacitors
}

$\operatorname{AUTHOR}(S)$ :

Baba, Masahiko; Kikuchi, Tatsuya; Suzuki, Ryosuke O.

\section{CITATION:}

Baba, Masahiko ...[et al]. Niobium powder synthesized by calciothermic reduction of niobium hydroxide for use in capacitors. Journal of Physics and Chemistry of Solids 2015, 78: 101-109

ISSUE DATE:

2015-03

URL:

http://hdl.handle.net/2433/193298

\section{RIGHT:}

(C) 2014 Elsevier Ltd.; This is not the published version. Please cite only the published version.; この論文は出版社版でありません。引用の際に は出版社版をご確認ご利用ください。 


\title{
Niobium Powder Synthesized by Calciothermic Reduction of Niobium Hydroxide for Use in Capacitors
}

\author{
Masahiko Baba, ${ }^{1,2,3}$ Tatsuya Kikuchi, ${ }^{2}$ and Ryosuke O. Suzuki ${ }^{1,2, *}$ \\ ${ }^{1}$ Department of Energy Science and Technology, Graduate School of Energy Science, \\ Kyoto University, Sakyo-ku, Kyoto 606-8501 Japan \\ ${ }^{2}$ Division of Materials Science and Engineering, Faculty of Engineering, Hokkaido \\ University, Kita-13 Nishi-8, Kita-ku, Sapporo, Hokkaido, 060-8628 Japan \\ ${ }^{3}$ Research Center, Godo-Shigen Co. Ltd., Chiba, 297-0033 Japan
}

\begin{abstract}
Metallic niobium powder was produced for applications in electric capacitors via calciothermic reduction of niobium hydroxide in molten $\mathrm{CaCl}_{2}$. Sub-micrometer spherical metallic particles with coral-like morphologies reflected the particle size of the starting oxide powder. A fine powder was obtained from the mixtures of niobium hydroxide and $\mathrm{CaO}$ or $\mathrm{Ca}(\mathrm{OH})_{2}$, respectively.

Sintered pellets of the metallic powder showed a higher capacitance (CV) than those of the simply reduced powder without pre-treatment, because the shrinkage during sintering was smaller. The CV was as large as that of commercially sintered pellets for tantalum capacitors. Therefore, this niobium powder would act as a higher-voltage capacitor by applying chemical anodic treatment at higher voltages, and a lower oxygen content in the reduced power could realize a lower leak current.
\end{abstract}

\section{Keywords}

Electronic materials; Elements; Electrical properties; Crystal growth; Chemical synthesis

* Corresponding author: e-mail: rsuzuki@eng.hokudai.ac.jp,

TEL: +81 11706 6339, FAX.: +81 117066342 


\section{Introduction}

Tantalum (Ta) powder is primarily utilized for the production of capacitors in electronic devices commonly found in automobiles, cellular phones, personal computers, and gaming devices. However, Ta powder tends to be more expensive because of the rarity of its ores and the specificity of its accumulation. Soon it will be difficult to respond to the market requirements for cheaper electronic devices.

Niobium (Nb) powder is an attractive alternative of Ta powder, because $\mathrm{Nb}$ and its oxide have similar properties to those of Ta and its oxide, and because $\mathrm{Nb}$ ore is stably supplied at a reasonable price [1]. High purity $\mathrm{Nb}$ powder can be produced by the reduction of $\mathrm{K}_{2} \mathrm{NbF}_{7}$ by liquid sodium ( $\mathrm{Na}$ ) in molten salts [2], or by the reduction of $\mathrm{Nb}_{2} \mathrm{O}_{5}$ by magnesium (Mg) vapor or $\mathrm{Mg}+\mathrm{H}_{2}$ gas [3-6], for example. The first method is similar to the method used in the preparation of Ta powder where $\mathrm{K}_{2} \mathrm{TaF}_{7}$ is reduced by liquid $\mathrm{Na}$ [2,7-10]. Applying the current technologies in the Ta industry for $\mathrm{Nb}$ powder preparation may be technically facile. Notably, the particle size distribution and morphology of $\mathrm{Nb}$ powder will be controlled by certain operating conditions such as the mass balance between the molten salt and the raw material, stirring during the reaction, and feeding conditions of the raw materials [2,7-10]. However, with this method, the production cost of $\mathrm{Nb}$ powder will become similar to that of Ta powder. As a result, the price of $\mathrm{Nb}$ powder will also become high.

The latter method (Mg reduction) can produce fine $\mathrm{Nb}$ particles corresponding to the starting oxide particles [3-6]. However, it is difficult to control the grain size distribution and morphology so that they are suitable for applications in capacitors. This is partially because the significant exothermal heat that accompanies the chemical reaction is not released from the reaction field and the sintering of the produced particles becomes locally significant.

Powders used for capacitors should be very fine because a larger surface area can guarantee a larger capacitance. The authors propose to replace $\mathrm{Mg}$ with calcium (Ca) in the reduction process. Specifically, calciothermic reduction in molten $\mathrm{CaCl}_{2}$ was utilized to produce fine $\mathrm{Ta}$ and $\mathrm{Nb}$ powders directly from $\mathrm{Ta}_{2} \mathrm{O}_{5}$ and $\mathrm{Nb}_{2} \mathrm{O}_{5}$, respectively [11-17]. Note that these oxides are much cheaper than $\mathrm{K}_{2} \mathrm{TaF}_{7}$ and $\mathrm{K}_{2} \mathrm{NbF}_{7}$, respectively.

The overall reaction in the calciothermic reduction could be given as follows:

$$
\begin{aligned}
& \mathrm{Ta}_{2} \mathrm{O}_{5}+5 \mathrm{Ca}\left(\text { in } \mathrm{CaCl}_{2}\right)=2 \mathrm{Ta}+5 \mathrm{CaO}\left(\text { in } \mathrm{CaCl}_{2}\right) \\
& \mathrm{Nb}_{2} \mathrm{O}_{5}+5 \mathrm{Ca}\left(\text { in } \mathrm{CaCl}_{2}\right)=2 \mathrm{Nb}+5 \mathrm{CaO}\left(\text { in } \mathrm{CaCl}_{2}\right)
\end{aligned}
$$

Thermodynamically Ca was selected as the reductant because of its strong affinity to oxygen [18]. The coexistence of molten $\mathrm{CaCl}_{2}$ effectively enhanced the direct reduction of the oxides because the film of the reaction by-product, $\mathrm{CaO}$, can be removed by dissolution into liquid $\mathrm{CaCl}_{2}[19,20]$. Residual oxygen in the reduced metal can be eliminated by the lower activity of $\mathrm{CaO}$ in molten 
$\mathrm{CaCl}_{2}$. The coexistence of liquid $\mathrm{CaCl}_{2}$ can effectively release exothermic heat to the bulk and suppress the severe sintering of the produced particles during the reduction process [19,20].

The simple reactions shown in Eqs. (1) and (2) successfully produced fine powders with low oxygen contents, and the spherical particles were slightly sintered like a coral [11-16]. This powder morphology was similar to that observed in the conventional Na reduction of $\mathrm{K}_{2} \mathrm{NbF}_{7}$ [7-10]. The coral structure was also reported in the calciothermic reduction from $\mathrm{TiO}_{2}[11,19,20]$. This is probably because the skeleton of oxide particles was preserved after the removal of oxygen from the oxide particles. Superior conductivity and a large capacitance are expected in capacitors with lower oxygen concentrations and larger particle surfaces because individual fine particles are connected with good electrical conductivity [16,17].

In addition to Eqs. (1) and (2), Okabe et al. [12] reported an unique mechanism that the reaction in $\mathrm{CaCl}_{2}$ melt could be electrochemically mediated by electron transfer through the external circuit, and that the electron conductive media such as a metallic lead between the oxide and reductant could accelerate oxygen removal from the oxide. When the reductant was electrically separated from the oxide, the morphology did not change significantly [13], and this work will examine the effects of calciothermic reactions by separating from the electron mediated reaction and by considering the practical application.

In the mining industry, raw oxides in non-ferrous metallic ores are generally treated in wet chemical processes to remove impurities [1,2]. Intermediate products such as amorphous hydroxides are normally served for oxide preparation or conversion processes to second intermediate products such as $\mathrm{K}_{2} \mathrm{NbF}_{7}$. Hydroxide is seldom supplied as a raw material for direct reduction. This is probably because the volume of hydroxide per single metallic atom is large and because excess reductant is needed to remove hydroxide ions. However, the reduction of hydroxide has the potential to produce very fine particles if the skeleton of the hydroxide, with a density lower than that of oxide, can be maintained even after the reduction.

The purpose of this work is to investigate the calciothermic reduction of non-crystalline hydroxides in molten $\mathrm{CaCl}_{2}$ with some pre-treatment. The morphologies of the obtained powder as capacitors were studied. A characteristic feature of this method is the well-isolated fine powder preparation. The apparent chemical reaction can be given as Eq. (3):

$$
2 \mathrm{Nb}(\mathrm{OH})_{5} \cdot n \mathrm{H}_{2} \mathrm{O}+5 \mathrm{Ca}\left(\text { in } \mathrm{CaCl}_{2}\right)=2 \mathrm{Nb}+5 \mathrm{CaO}\left(\text { in } \mathrm{CaCl}_{2}\right)+(2 n+5) \mathrm{H}_{2} \mathrm{O}(\mathrm{g})
$$

where a significant amount of exothermic heat ( $673 \mathrm{~kJ} / \mathrm{molNb}$ at $n=0$ and $1173 \mathrm{~K}$ [15]) is released. The local sintering or coarsening of the particles due to the exothermic heat will be minimized via thermal transfer to the surrounding molten salt. As a result, an interesting morphology will be realized in that needle-, branch-, or plate-like particles and it will coexist with fine and spherical 
particles. The forming conditions and the electric properties of these unique morphologies will be reported and compared to the calciothermic reduction of $\mathrm{Nb}_{2} \mathrm{O}_{5}$ and its coral-like $\mathrm{Nb}$ powder $[11,12,16,21]$. It is noted that the required quantity of Ca per $\mathrm{Nb}$ atom is $2.5 \mathrm{~mol}$ both in Eq. (2) and (3).

The preferential reaction site, whether the reduction occurs in the molten salt or on the oxide particles, is also interesting. Yuan and Okabe [22-24] showed the possible mechanism of reduction in $\mathrm{KCl}-\mathrm{NaCl}-\mathrm{MgCl}_{2}-\mathrm{DyCl}_{2}$ melt that the reductant, $\mathrm{Dy}^{2+}$, dissolved in the melt can react with Ta ions also dissolved in the melt to form Ta powder. They reported that the reaction product, $\mathrm{Dy}^{3+}$, is reduced by either electrochemical or magnesiothermic reduction at the cathode and regenerated to reductant $\mathrm{Dy}^{2+}$. The authors thought that their unique idea $\left(\mathrm{Dy}^{2+} / \mathrm{Dy}^{3+}\right)$ in $\mathrm{MgCl}_{2}$ based salt may be expanded to the other molten salt such as $\left(\mathrm{Ca} / \mathrm{Ca}^{2+}\right)$ in $\mathrm{CaCl}_{2}-\mathrm{CaO}$ melt. Although Ca metal can dissolve in a $\mathrm{CaCl}_{2}$ melt and react with the oxide, most previous studies reported that the reduction occurs on the surface of the solid oxide particles.

\section{Experimental}

\subsection{Pre-treatments and Procedures}

High purity niobium hydroxide was supplied by Zhongguoguoyougong-sijiatezhi in China. Hereafter, it will be referred to as raw material Type I. This white powder was treated in the following three ways prior to reduction to yield raw material Type II, III, and IV.

Raw material Type II was produced from raw material Type I by sol-gel dehydration. Raw material Type I was mixed with hydrous $\mathrm{Ca}(\mathrm{OH})_{2}(99.9 \%$ in metallic purity) and distilled water in a molar ratio of raw material Type I : $\mathrm{Ca}(\mathrm{OH})_{2}: \mathrm{H}_{2} \mathrm{O}=1: 1: 2$, where the chemical formula of the raw material Type I was assumed to be $\mathrm{Nb}(\mathrm{OH})_{5}$. The $\mathrm{pH}$ of the gel was 13-13.5. This white gel was filled in a niobium crucible (75 mm in ID., $65 \mathrm{~mm}$ high), and heated at $573 \mathrm{~K}$ for $3.6 \mathrm{ks}$ and subsequently at $773 \mathrm{~K}$ for $3.6 \mathrm{ks}$ in vacuum evacuated continuously by rotary pump. There was no apparent shrinkage during heating. After cooling, the sample was pulverized in an agate mortar and used as raw material Type II.

Raw material Type III was prepared as follows: The calcined $\mathrm{CaO}$ (99.9\%) and raw material Type I were mixed in a 1:1 molar ratio and pressed into cylindrical pellets $(5 \mathrm{~mm}$ in diameter, $10 \mathrm{~mm}$ high). The pellets were heated at $773 \mathrm{~K}$ for $3.6 \mathrm{ks}$ under vacuum evacuated continuously by rotary pump. Only raw material Type III was utilized as the pellets for reduction.

Raw material Type IV was prepared as follows: $\mathrm{NaOH}$ was used in the Sol-Gel method as the alternative of $\mathrm{Ca}(\mathrm{OH})_{2}$ utilized to produce raw material type II. The mixing molar ratio of $\mathrm{Nb}(\mathrm{OH})_{5}$ : $\mathrm{NaOH}: \mathrm{H}_{2} \mathrm{O}$ was $1: 2: 2$. The white gel was similarly heated at $573 \mathrm{~K}$ for $3.6 \mathrm{ks}$ and at $773 \mathrm{~K}$ for $3.6 \mathrm{ks}$ under vacuum. The pulverized sample was used as raw material Type IV.

Oxide Type $\mathrm{V}$ is niobium oxide, $\mathrm{Nb}_{2} \mathrm{O}_{5}$ (99.9\%), which was supplied by Mitsui Metals Ltd. 


\subsection{Procedures for Reduction}

Detailed procedures for the reduction, sintering, and evaluation of electric properties were previously reported for Ta powder [11,13-17]. The procedures used in this study were based on these reports, and a brief outline and some modifications are given below.

Metallic calcium lumps (99.8\% pure), $\mathrm{CaCl}_{2}$ powder (99.9\%), and one of the raw materials, were filled in the Nb crucible in that order. The crucible was heated in stainless steel vessel, as shown in Fig. 1.

At a reaction temperature above the melting points of $\mathrm{Ca}$ and $\mathrm{CaCl}_{2}$, the lighter $\mathrm{Ca}$ flows upwards and the heavier raw material sinks on the bottom of crucible due to the difference in density, as illustrated in Fig. 1. The reverse arrangement of the starting materials was reported to enhance the calciothermic reduction of $\mathrm{Ta}_{2} \mathrm{O}_{5}$ to form broccoli-like powders [14-17]. Those samples were reacted at $1153 \mathrm{~K}$ for $7.2 \mathrm{ks}$ in an Ar gas atmosphere, and the molar ratio of the raw material : Ca reductant : $\mathrm{CaCl}_{2}$ solvent was set as $1: 30: 60$. These conditions were optimized for Ta [16], and they were also utilized for this work.

After the reduction of the raw material, the sample was cooled in Ar gas and the solidified salt and excess calcium were removed in a dilute aqueous $\mathrm{HCl}$ solution at $333 \mathrm{~K}$. The sample powder was rinsed with distilled water, filtered, and dried under vacuum.

\subsection{Analysis}

The phases in the sample were identified by X-ray diffraction (XRD) using $\mathrm{Cu}-\mathrm{K} \alpha$ ray at room temperature. The morphology of the sample was examined using a scanning electron microscope (SEM) equipped with an energy dispersive X-ray (EDX) analyzer. The oxygen and nitrogen concentration were analyzed by inert-gas extraction - infrared absorption method. Metallic impurities were wet-chemically analyzed after dissolution in HF solution using atomic absorption spectrometry (AAS) and inductively coupled plasma-atomic fluorescence spectrometry (ICP-AFS). The specific surface area of the powder was analyzed using automatic gas adsorption by employing the Brunauer-Emmett-Teller (BET) method. The optical distribution of the particle size was counted using laser light scattering.

The dehydration of raw material Type I was monitored in air by differential thermal analysis and simultaneous thermal gravimetric measurements (TG/DTA) at the heating rate of 1/12 K/s. In-situ high temperature X-ray diffraction (HT-XRD) was measured using Mo- $\mathrm{K}_{\alpha}$ ray in air by heating raw material Type I on a platinum heating plate.

\subsection{Sintering and evaluation of electric properties}

The metallic powder $(0.417 \mathrm{~g}$ ) and camphor ( 2 mass \%) were mixed and pressed into a cylindrical 
pellet that was $5 \mathrm{~mm}$ in diameter. A Ta wire $(0.49 \mathrm{~mm}$ in diameter) was inserted in pressing. This was used as the electric lead for dielectric measurements after sintering. The pellets were heated at $673 \mathrm{~K}$ in a vacuum to completely evaporate the camphor. The pellets were subsequently heated in a vacuum for $1.2 \mathrm{ks}$ at 1273 or $1473 \mathrm{~K}$. The density of the sintered body was evaluated from the volume and mass, after subtracting those of the inserted Ta wire.

The dielectric oxide film on the niobium powder was formed in 0.5 vol\% $\mathrm{H}_{3} \mathrm{PO}_{4}$ solution at $363 \mathrm{~K}$ [25]. Three pellets were simultaneously immersed for $7.2 \mathrm{ks}$ at $60 \mathrm{~mA} / \mathrm{g}$ after applying a voltage of 20 or $50 \mathrm{~V}$.

The capacitance (CV), leak current (LC), and dielectric energy loss of the capacitor (tangent of loss angle; $\tan \delta$ ), were measured by the standard wet method for tantalum capacitors [26], because an international standard method for niobium capacitors was not yet regulated. $\tan \delta$ was deduced from

$$
\tan \delta=2 \pi f c \cdot(\mathrm{ESR})
$$

where $f$ and $c$ are the frequency in $\mathrm{Hz}$ and capacity in $\mathrm{F}$, respectively, and ESR is the measured equivalent serial resistance.

For $\mathrm{CV}$ and $\tan \delta$, three samples were immersed for $0.6 \mathrm{ks}$ at $298 \mathrm{~K}$ in a $30.5 \mathrm{vol} \% \mathrm{H}_{3} \mathrm{PO}_{4}$ solution, and a sine signal of $120 \mathrm{~Hz}$ was applied at $1.5 \mathrm{~V}$. For LC, the sample was immersed in a 10 vol\% $\mathrm{H}_{3} \mathrm{PO}_{4}$ solution for $0.6 \mathrm{ks}$ at $298 \mathrm{~K}$. LC was measured at $180 \mathrm{~s}$ after applying $14.0 \mathrm{~V}$.

\section{Results and Discussions}

\subsection{Raw materials}

Fig.2 shows the SEM images of the raw starting materials. The as-received Type I material existed as sub-micron sized, spherical particles. It had a similar morphology to that of raw material Type II that was calcined with $\mathrm{Ca}(\mathrm{OH})_{2}$. No segregation of elemental Ca was observed in raw material Type II by SEM/EDX analysis, and Ca was homogeneously distributed on the surface of the Nb hydroxide particles. SEM observations for raw materials Type III and IV could not be conducted because of their strong hygroscopic nature. Larger particles existed in the as-received oxide Type V, as shown in Fig.2(c), and the secondary grains (approximately $1 \mathrm{~mm}$ in diameter) were porous.

Table 1 lists the phase identification of the raw materials as determined by XRD. Raw material Type I was non-crystalline, as judged from the broad diffractions shown in Fig.3. Raw material Type $\mathrm{V}$ was a mixture of two crystalline symmetries of $\mathrm{Nb}_{2} \mathrm{O}_{5}, \mathrm{P}_{2}$, and $\mathrm{P}_{b a m}[27,28]$, although many crystalline structures are known for $\mathrm{Nb}_{2} \mathrm{O}_{5}$ depending on annealing temperatures, preparation methods, etc [27-29]. The apparent morphology of raw material Type $\mathrm{V}$ was homogeneous as shown in Fig.2(c), and the crystalline structure could not be distinguished from the crystalline shapes. 
Because $\mathrm{Ca}(\mathrm{OH})_{2}$ decomposes to $\mathrm{CaO}$ and $\mathrm{H}_{2} \mathrm{O}$ when it is kept at $773 \mathrm{~K}$ (water vapor pressure of $\mathrm{Ca}(\mathrm{OH})_{2}$ is $\left.0.71 \mathrm{~atm}[18]\right)$, the added $\mathrm{Ca}(\mathrm{OH})_{2}$ was identified as $\mathrm{CaO}$ in Type II. The XRD measurements for raw material Type III and IV failed due to strong deliquescence during the measurements. These raw materials were stored under vacuum and set in the furnace within $3.6 \mathrm{ks}$ prior to the reduction experiments.

Fig.4 shows the TG/DTA curves measured in air for raw material Type I. The mass loss was primarily due to dehydration during heating. Water removal began immediately after heating from room temperature, but the non-crystalline structure at room temperature was maintained until $423 \mathrm{~K}$, as shown in the in-situ HT-XRD (Fig.5). Therefore, the mass loss below $423 \mathrm{~K}$ was due to the removal of water adhered to the sample. At $673 \mathrm{~K}$, the sample became amorphous, and different from the non-crystalline structure present below $423 \mathrm{~K}$. As shown in Fig. 4, the sample completely lost water over $700 \mathrm{~K}$. An exothermic reaction was observed at about $800 \mathrm{~K}$. The phase identifications at 1073 and $1273 \mathrm{~K}$ indicated the formation of orthorhombic $\mathrm{Nb}_{2} \mathrm{O}_{5}$ [28]. Therefore, it was confirmed that raw material Type I was converted to $\mathrm{Nb}_{2} \mathrm{O}_{5}$ at $800 \mathrm{~K}$, which is lower than the reduction temperature.

The chemical formula of raw material Type I can be deduced to be $\mathrm{Nb}(\mathrm{OH}) \mathrm{O}_{2} \cdot \mathrm{H}_{2} \mathrm{O}$, because the mass loss was evaluated to be approximately $16.9 \%$ at $1200 \mathrm{~K}$. Based on the thermal analysis shown in Fig.5, it is estimated that $\mathrm{Nb}(\mathrm{OH}) \mathrm{O}_{2} \cdot \mathrm{H}_{2} \mathrm{O}$ loses water to form $\mathrm{Nb}(\mathrm{OH}) \mathrm{O}_{2}$ by $423 \mathrm{~K}$, decomposes to amorphous $\mathrm{Nb}_{2} \mathrm{O}_{5}$ which is accompanied by a mass loss at $673 \mathrm{~K}$, and finally crystallizes at about $873 \mathrm{~K}$. Although three crystalline structures are known for crystalline $\mathrm{Nb}(\mathrm{OH}) \mathrm{O}_{2}$ [29], none of the corresponding diffraction lines agreed with those found in this study.

Raw materials Type I - IV were heated in an Ar gas flow for $3.6 \mathrm{ks}$ at $573 \mathrm{~K}$ prior to reduction in order to remove the adhered water, and the hydroxides were decomposed at $773 \mathrm{~K}$. Gaseous water was not transferred to the coexisting $\mathrm{CaCl}_{2}$ because the temperatures exceed the dehydration temperature of $\mathrm{CaCl}_{2}$ (approximately $493 \mathrm{~K}$ ). Gaseous water may have been exhausted out to the apparatus. In summary, the raw materials starting from Type I were converted to $\mathrm{Nb}_{2} \mathrm{O}_{5}$ during heating well below the reduction temperature. All the used raw materials would have a chemical formula of $\mathrm{Nb}_{2} \mathrm{O}_{5}$ at the reducing atmosphere of $1153 \mathrm{~K}$, although their crystalline symmetries were different.

\subsection{Reduced powders}

In general, all powders obtained after reduction at $1153 \mathrm{~K}$ for $7.2 \mathrm{ks}$ were fine and black. The XRD measurements at room temperature identified a single phase of metallic $\mathrm{Nb}$, after the powders were removed from the solidified salt, washed, rinsed, and dried.

Table 2 summarizes the chemical analysis of the 5 obtained powders and their specific surface areas. Because $\mathrm{Nb}$ can absorb oxygen as a solid solution (the maximum solubility is 0.31 mass\% 
oxygen at $1153 \mathrm{~K}$ [30]), the oxygen level is not crucial in this work. The oxygen contents in the reduced Type II and IV samples were about 20-30\% higher than those of the other powders. The specific surface area of Type II was the largest, judging from the BET value. A thin oxidized layer on the particle surface may form during handling after the reduction, and may constitute one of the reasons why the oxygen level of Type II was higher than those of the others. Moreover, this layer in Type II will be thinner than those on the other particle surfaces. Notably, thinner surface areas are favorable for capacitor applications.

Comparing with the oxygen levels in Type IV and V, Type IV powder was not well deoxidized. This is probably due to the coarsening of Type IV particles, as the Ca content in the reduced powders was not very high. Reduced powders can coexist with $\mathrm{CaO}$ if the dissolution of $\mathrm{CaO}$ into the salt is imperfect. If the particles combine, some parts of $\mathrm{CaO}$ will be surrounded by the metallic particles, and the analytical oxygen content of the sample will become high because of the coexistence of $\mathrm{CaO}$.

A fairly large amount of Ca remained in the reduced powders. Some was likely due to residual Ca reductant. The by-product, $\mathrm{CaO}$, also potentially remained in the sample. Other potential Ca sources include $\mathrm{CaO}$ from the pre-treatment and $\mathrm{CaCl}_{2}$ from the supporting media, although the powdery sample was thoroughly washed and rinsed several times. Higher Ca contents were detected in Type III, IV, and V. This may be related to the powder morphology as these powders had complicated morphologies that may not be amenable to the complete removal of $\mathrm{CaO}$ and $\mathrm{CaCl}_{2}$. Note that the $\mathrm{Na}$ concentration in the reduced sample from raw material Type IV (sol-gel treated with $\mathrm{NaOH}$ ) was not as high as those from the other samples, thus supporting the conclusion that the procedure for the removal of attached $\mathrm{CaCl}_{2}$ had no great issue in washing.

\subsection{Morphology of reduced powders}

The morphologies, as determined by SEM, are shown in Fig. 6. Fine powders consisting of primary particles smaller than $1 \mu \mathrm{m}$ were obtained in Type I, IV, and V. Their primary particles were approximately spherical and connected in the form of a coral.

The morphology of the Type IV reduced powder was similar to that of Type I, although raw material Type IV contained $\mathrm{NaOH}$. Notably, $\mathrm{NaOH}$ melts at $596 \mathrm{~K}$, well below the reduction temperature of $1153 \mathrm{~K}$. Whether or not $\mathrm{NaOH}$ can mix with $\mathrm{CaCl}_{2}$ is unknown. Thermodynamically, $\mathrm{NaOH}$ can be reduced by a high concentration of Ca to form a Ca-Na liquid alloy, as shown in Eq. 5.

$$
\begin{aligned}
& 2 \mathrm{NaOH}+2 \mathrm{Ca}=2 \mathrm{CaO}+\mathrm{H}_{2}(\mathrm{~g})+2 \mathrm{Na} \\
& \qquad \Delta G^{0}=-480.44 \mathrm{~kJ} / \mathrm{mol} \text { at } 1173 \mathrm{~K}[18]
\end{aligned}
$$

The less reducibility and slower reduction rate presented a concern because of reductant loss by 
consumption due to the reduction of $\mathrm{NaOH}$ and because of the lower activity of $\mathrm{Ca}$ by alloying. However, using twice the amount of moles of $\mathrm{NaOH}$ to the hydroxide did not affect the reduction behavior of raw material Type IV.

Raw material Type V contained two crystalline symmetries of $\mathrm{Nb}_{2} \mathrm{O}_{5}$, but its morphology after the reduction was similar to those of Type I and IV. As such, a clear relationship between the crystalline symmetry and the morphology of the reduced powder could not be determined.

In the calciothermic reduction of Ta oxide, the morphology of oxide particles is reflected in that of the reduced metallic particles [13-16]. Because $\mathrm{Ta}_{2} \mathrm{O}_{5}$ is reduced directly to metallic Ta particles, not via intermediate phases, the morphology of starting Ta oxide affects the morphology of the metallic particles. However, because all the crystalline forms of $\mathrm{Nb}_{2} \mathrm{O}_{5}$ were reduced through lower oxides such as $\mathrm{NbO}_{2}$ and $\mathrm{NbO}$, the morphology of the lower oxides may become dominant and the morphology of the metallic particles might become similar.

As shown in Fig. 6(b), characteristic dendrite-like or bar-like particles in addition to spherical particles were observed in the SEM image of the reduced Type II sample. This morphology differed from that of the starting material (Fig. 2(b)).

As shown in Fig. 6(c), the sample reduced from Type III starting material also exhibited a unique morphology. Most of reduced particles were 2-10 $\mu \mathrm{m}$ long plates. The starting material was compressed with $\mathrm{CaO}$ particles and served as the reduction pellets, rather than powder. Therefore, the metallic particles may be sufficiently sintered after reduction. Notably, the plate-like particles could be produced only from the reduction of hydroxide, and could not be formed in general procedures of mechanical crashing or the hydration/dehydration of metallic ingots [31].

\subsection{Mechanisms of Particle Formation}

Dendritic or bar-like morphologies of the metallic particles were obtained only by the reaction combined with $\mathrm{Ca}, \mathrm{CaO}$, and $\mathrm{CaCl}_{2}$ after the sol-gel treatment using $\mathrm{Ca}(\mathrm{OH})_{2}$. During the sol-gel treatment in basic solution with $\mathrm{Ca}(\mathrm{OH})_{2}$, a strong bond between $\mathrm{Ca}$ and $\mathrm{Nb}$ atoms may be formed in the amorphous structures, and this bonding is maintained even after water removal. Even during $\mathrm{CaO}$ dissolution in the $\mathrm{CaCl}_{2}$ melt, this frame structure might be reserved as a one dimensional chain. $\mathrm{NaOH}$ and $\mathrm{Na}_{2} \mathrm{O}$ may not affect the Nb-O binding and dissolve without interacting with $\mathrm{Nb}$ hydroxide. Although strong interactions between Nb-O-Ca are still ambiguous, the existence produces dendritic or bar-like morphologies.

Calcium reduction is enhanced by the dissolution of the reaction by-product, $\mathrm{CaO}$, into molten $\mathrm{CaCl}_{2}[11,13-17,19,20]$. In raw material Type II, the surfaces of the Type I particles were tightly coated with $\mathrm{CaO}$ particles, and only a select portion of the oxide surface started a strong exothermic reaction with Ca. Normally the evolution of heat enhances sintering with the closest particles. However, a portion of the heat may be consumed for the one-dimensional growth. 
Raw material Type III ( $\mathrm{CaO}$ was pressed with type I particles) proceeded a very strong exothermic reaction with $\mathrm{Ca}$, and that the raw material was probably exposed to higher temperatures. Although the molten $\mathrm{CaCl}_{2}$ could extract the reaction heat from local reaction positions, it would be insufficient. As a result, the Type III and Type IV particles sintered tightly and three dimensionally in a short period of time.

The third reason why one dimensional bars and two dimensional plates were formed during the reduction is the possible existence of intermediate oxide or hydroxide with a lower valency, such as $\mathrm{NbO}_{2}, \mathrm{NbO}$, or " $\mathrm{NbCaO}_{2}$ ". If these crystalline particles have a favorable cracking nature during oxygen removal, $\mathrm{Nb}$ grains with an interesting morphology will be explained. However, such intermediate products were not identified in the present study, and the detailed mechanism will be investigated in the near future.

At present, we conclude that the strange morphology of the raw material Type II reduced particles is closely related to the adhesion of $\mathrm{CaO}$, which formed a thin layer but was tightly to the hydroxide particles.

\subsection{Density of Sintered Powders}

It is expected as the $\mathrm{Nb}$ capacitor with a good quality that an apparent shape change of the $\mathrm{Nb}$ pellet does not occur during heat treatments. Namely, a large open spacing among the metallic particles should be maintained even after the heat treatments, because the sintered pellet is used as the anode in the capacitor after adding the liquid electrolyte into the spaces among the particles. Previously, in the calciothermic reduction of $\mathrm{Ta}_{2} \mathrm{O}_{5}$, it was reported that metallic Ta was obtained as a powder with broccoli-like morphology [14-17] and that it could maintain the porous property even after sintering $[16,17]$. The Type II powder obtained in this paper is similar to previous reports and is expected to hold excellent electronic properties. However, Type III powder is not expected to have good electronic properties, because the Type III particles were coarser and their specific surface area was smaller. Because the morphology of Type IV was similar to that of Type I, its character was not studied, partially because the amount of Type IV obtained was too small. Therefore, the degree of shrinkage during sintering as capacitors was examined only in three powders: Type I, II, and V.

The density change due to sintering was analyzed. $D g$ and $D$ s are defined as the apparent density of the pellet before and after sintering, respectively. Dg was experimentally controlled to be 2.5 $\mathrm{Mg} / \mathrm{m}^{3}$, although the real density of metallic niobium is $8.57 \mathrm{Mg} / \mathrm{m}^{3}$ [18]. Table 3 shows the density after the sintering, $D$ s. When the sample pellet shrinks during sintering, $D$ s becomes larger. The ratio of $D \mathrm{~s} / D \mathrm{~g}$ is a good index of shrinkage. As shown in Table 3, a significant shrinkage occurred during sintering at $1473 \mathrm{~K}$ for the Type I reduced powder, and the dimension of its pellet could not be measured accurately because of irregular deformation. The $D \mathrm{~s} / D \mathrm{~g}$ index for Type II and V was similar at $1373 \mathrm{~K}$. However, the shrinkage of Type V at $1473 \mathrm{~K}$ was sufficiently significant that 
$D$ s/Dg was clearly larger in Type V than in Type II. In conclusion, the best data was obtained below $1373 \mathrm{~K}$ at Type I and II.

\subsection{Electronic Properties}

(a) Anodizing at $20 \mathrm{~V}$

Anodizing significantly depends on the spacing among the particles in the sintered sample. Therefore, the samples with $D \mathrm{~s} / D \mathrm{~g}$ of about 1 were examined. To evaluate the electronic properties, 5 samples were selected: Type I sintered at $1373 \mathrm{~K}$, as well as Type II and V at $1373 \mathrm{~K}$ and $1473 \mathrm{~K}$.

Table 4 shows the results of these samples after sintering for $1.2 \mathrm{ks}$ at the aforementioned temperatures and anodic oxidation. The anodizing voltage was set at $20 \mathrm{~V}$ where the capacitor film was formed on the surface of Nb. The CV of Type II was $20 \%$ higher than that of Type I and V at all temperatures, as shown in Table 4. The CV of Type II was equivalent to that of commercial "high CV capacitor" products made of tantalum. This suggests the future viability of this $\mathrm{Nb}$ powder as a capacitor.

The phase delay, $\tan \delta$, of Types I-IV was not suitable when the powders were sintered at $1373 \mathrm{~K}$. However, when Type II was sintered at $1473 \mathrm{~K}$, tan $\delta$ was sufficiently high for practical usage.

The leak current, LC, was commonly high and not applicable for capacitor applications. The LC of Type I and Type II (hydroxide raw materials) were three times higher than the LC of Type V (oxide as raw material). Generally in Ta capacitors, the LC value increases when the sample contains a larger amount of oxygen. The residual oxygen contents in the 3 reduced powders were high. This high oxygen contamination, as shown in Table 1, is one of the reasons why the LC values of the $\mathrm{Nb}$ samples were so high. However, the LC values of the three samples were not the same. This difference may come from the different morphologies of the reduced particles due to a difference in the raw materials. The oxygen concentration in Ta powder could be lowered by optimizing the reducing temperature and time $[15,16]$, and this kind of optimization is also needed for $\mathrm{Nb}$ powders.

\section{(b) Anodizing at $50 \mathrm{~V}$}

The electronic properties at higher voltages were studied in order to examine the applicability as capacitors at high voltages such as $24-28 \mathrm{~V}$, where the current market shows a strong demand. The experimental procedures were similar to the anodizing at $20 \mathrm{~V}$. Some modifications include an anodizing voltage of $50 \mathrm{~V}$, current increase to $60 \mathrm{~mA}$ per $1.0 \mathrm{~g}$ Nb sample, and continuous current for $7.2 \mathrm{ks}$. A thicker and denser oxide film is expected during anodization under these conditions, and the higher anodizing voltage is critical to this film formation.

The results at the higher anodizing voltage are shown in Table 4. All three sintered pellets were broken during anodization, and their electronic properties could not be further evaluated. Sintered pellet Type V was successively anodized, but the characterization could not be carried out even if the 
voltage was applied because the anodization proceeded not only at the thin surface but also at the deep parts of the particles, and the entire body might be oxidized. Then the sintered pellets cracked and electric charges could not be applied to the sintered samples. It is judged at this stage that these samples are hardly applied to the high voltage capacitor tests.

Hereafter, only the results of Type II pellets will be reported. As shown in Table 4, the CV of the Type II sample sintered at $1473 \mathrm{~K}$ was fairly high. Although the CV of the sample anodized at $50 \mathrm{~V}$ was about $10 \%$ lower than that at $20 \mathrm{~V}$, the LC values and $\tan \delta$ were identical, suggesting that the Type II powder could be applied as a capacitor resistant to higher voltages.

Fig. 7 shows the cross-sectional SEM image after cleavage of the sintered Type II samples. The formation of the thin anodized oxide layer is hardly seen on the surface of the Nb particles. The bar-like particles were homogeneously sintered even at the central part of the pellet, and the cross-section was macroscopically smooth. Although the individual particles were fine, it is surprising that open spaces still existed after sintering.

The Type II sample contained powders with needle-like, bar-like, and dendritic morphologies, and these long particles played an important role in suppressing the total shrinkage of the pellet. Many open pores remained in the sample, and a sufficient anodization treatment could be performed even at the central part of pellet. This effect was already reported in Ta particles [16]. No other materials have been reported, except for flaky Ta powder [31], for use as capacitors resistant to higher voltages. It is expected that inexpensive $\mathrm{Nb}$ can replace Ta in higher voltage fields, for example, in fuel cell applications. The dendritic morphology of the Type II powder will be one of the best materials.

\section{Conclusions}

A solid metallic niobium powder was successively produced by reducing the solid oxide or hydroxide powders by calcium dissolution in a $\mathrm{CaCl}_{2}-\mathrm{CaO}$ melt. Generally, the reduced powders were fine, and of sub-micro meter size, reflecting the morphology of the raw material. The sintered pellet from these reduced powders showed identical electronic properties to those of commercially available Ta pellets. The Nb capacitors may be viable alternatives to Ta capacitors.

Notably, interesting morphologies of the dendritic, bar-like, or needle-like powders (Type II) were obtained by using the sol-gel treatment with $\mathrm{Ca}(\mathrm{OH})_{2}$. This morphology was quite different from the original particle morphology. A plate-like powder of Type III was obtained when $\mathrm{CaO}$ was utilized. These processes can be replaced for the long procedures of powder making starting from the metallic ingot via hydration/dehydration.

The reduced powder from Type II was subjected to sintering. Its shrinkage was less than the powder without any pre-treatment. The electronic properties of the sintered pellets were evaluated: a higher CV value was obtained than those obtained via other methods. This work shows that reduced 
powders are favorable for capacitors resistant to higher voltages, if the residual oxygen concentration can be suppressed.

\section{Acknowledgements}

The authors thank Ms K. Iwamoto and her staff at Aizu plant of Showa Cabot Supermetals (currently: Global Advanced Metals) for their analysis. This work was supported in part by Cabot Supermetals K.K. and Grants-in-Aid for Scientific Research under Contract No.14205109, 18360367 and 25289267. 


\section{References}

[1] T. Izumi, "Processing of Ta Powder at Cabot-Supermetals Aizu Plant," Journal of MMIJ (Shigen-to-Sozai), 123 (2007), pp. 711-714. (in Japanese)

[2] T. Izumi, "Processing of Metallic Material Prospect to the Next Generation. Powder Production Prospect of Tantalum and Niobium,” Kinzoku (Metals Science and Technology) (1999) 69 [10] 875 - 880. (in Japanese)

[3] L. N. Shekhter, T. B. Tripp, L. L. Lanin, K. Reichert, J. Vieregge, O. Thomas, "Reduction of Nb or Ta oxide powder by a gaseous light metal or a hydride thereof," US Patent Application PCT Pub. Number WO2000/067936, 5 May 1999.

[4] T. Konig, "Process for the Preparation of Finely Divided Metal and Ceramic Powders," US patent, US 5472477 A, 5 May 1992.

[5] I. Park, T. H. Okabe, Y. Waseda, H. S. Yu, O. Y. Lee, "Semi-continuous Production of Niobium Powder by Magnesiothermic Reduction of $\mathrm{Nb}_{2} \mathrm{O}_{5}$,” Mater. Trans., 42 [5] (2001) pp. 850-855. http://www.jim.or.jp/journal/e/42/05/850.html

[6] T. H. Okabe, N. Sato, Y. Mitsuda, S. Ono, "Production of Tantalum Powder by Magnesiothermic Reduction of Feed Preform", Mater. Trans., 44 [12] (2003) pp. 2646-2653. http://www.jim.or.jp/journal/e/44/12/2646.html

[7] C. K. Gupta, “Extractive Metallurgy of Niobium, Tantalum, and Vanadium”, Intern. Met. Rev. 29 [6] (1984) pp. 405-444. http://www.asminternational.org/imr-journal-search/-/journal_content/56/ 10192/IMR2906P405/PERIODICAL-ARTICLE

[8] A. Agulyansky, "The Chemistry of Tantalum and Niobium Fluoride Compounds", Elsevier, Amsterdam, The Netherlands, (2004).

[9] J.-S. Yoon, S. Goto, B. I. Kim, "Characteristic Variation of Niobium Powder Produced under Various Reduction Temperature and Amount of Reductant Addition,” Mater. Trans., 51 [2] (2010) pp. 354-358. DOI: 10.2320/matertrans.M2009192

[10] V. N. Kolosov, V. M. Orlov, M. N. Miroshnichenko, T. Yu. Prokhorova, "Preparation of Highpurity Tantalum Powders by Sodium Thermal Reduction,” Inorganic Materials, 48 [9] (2012) pp. 903-907. DOI: 10.1134/S0020168512080080. Originally published in Neorganicheskie Materialy, 48 [9] (2012), pp.1023-1027.

[11] R. O. Suzuki, M. Aizawa, K. Ono, "Calcium-deoxidation of Niobium and Titanium in Ca-saturated $\mathrm{CaCl}_{2}$ Molten Salt,” J. Alloy Compd., 288 [1-2] (1999) pp. 173-182. DOI: 10.1016/S0925-8388(99)00116-4

[12] T. H. Okabe, I. Park, K. T. Jacob, Y. Waseda, "Production of Niobium Powder by Electronically Mediated Reaction (EMR) Using Calcium as a Reductant,” J. Alloy. Compd., 288 [1-2] (1999) pp. 200-210. DOI: 10.1016/S0925-8388(99)00130-9

[13] M. Baba, Y. Ono, R. O. Suzuki, "Tantalum and Niobium Powder Preparation from Their Oxides 
by Calciothermic Reduction in the Molten $\mathrm{CaCl}_{2}$," J. Phys. Chem. Solids, 66 [2-4] (2004) pp. 466-470. DOI: 10.1016/j.jpcs.2004.06.042

[14] R. O. Suzuki, M. Baba, Y. Ono, K. Yamamoto, "Formation of Broccoli-like Morphology of Tantalum Powder", J. Alloy Compd., 389 [1-2] (2005) pp. 310-316. DOI: 10.1016/ j.jallcom.2004.08.016

[15] K. Yamamoto, R. O. Suzuki, Y. Ono, M. Baba, "Formation of Broccoli-like Morphology of Ta Powder", in “Molten Salt XIV”, ed. by R. A. Mantz, P. C. Trulove, H. C. DeLong, G. R. Stafford, M. Hagiwara, D. A. Costa, The Electrochemical Society, Penningston, NJ, USA, (2006) pp. 1052-1062. [16] R. O. Suzuki, M. Baba, K. Yamamoto, "Broccoli-like Powder of Ta and Nb by Ca Reduction of Their Oxides", Proc. 7th Int. Symp. on Molten Salts Chem. \& Techn., (29Aug.-02Sept. 2005, Toulouse, France), vol.2, pp. 1063-1066.

[17] M. Baba and R. O. Suzuki, "Dielectric Properties of Tantalum Powder with Broccoli-like Morphology", J. Alloys and Comp., 392 [1-2] (2005) pp. 225-230. DOI: 10.1016/j.jallcom.2004. 09.039

[18] A. Roine, "HSC chemistry", Ver.5.11, Outokumpu Research Oy, Poli, Finland (2005).

[19] R.O. Suzuki and S. Inoue, "Calciothermic Reduction of Titanium Oxide in Molten $\mathrm{CaCl}_{2}$," Metall. Mater. Trans. B, 34B [3] (2003) pp. 277-286. DOI: 10.1007/s11663-003-0073-2

[20] T. Kikuchi, M. Yoshida, Y. Taguchi, H. Habazaki, R. O. Suzuki, "Fabrication of a micro-porous Ti-Zr alloy by electroless reduction with a calcium reductant for electrolytic capacitor applications,” J. Alloys and Comp., 586 (2014) pp. 148-154. DOI: 10.1016/j.jallcom. 2013.10.052

[21] S. M. Jeong, H. Y. Yoo, J.-M. Hur, C.-S. Seo, "Preparation of metallic niobium from niobium pentoxide by an indirect electrochemical reduction in a $\mathrm{LiCl}_{-} \mathrm{Li}_{2} \mathrm{O}$ molten salt," J. Alloy Compd., 452 [1] (2008) pp. 27-31. DOI: 10.1016/j.jallcom.2007.02.057

[22] B. Yuan and T. H. Okabe, "Production of Fine Tantalum Powder by Electrochemical Method," Mater. Trans., 48 (10) (2007) pp. 2687-2694. DOI: 10.2320/matertrans.M-MRA2007876

[23] B. Yuan and T. H. Okabe, "Electrochemically Assisted Formation of Fine Niobium Powder in Molten Salt,” J. Electrochem. Soc., 154 (1) (2007) pp. E1-E7. DOI: 10.1149/1.2364842

[24] B. Yuan and T. H. Okabe, "Niobium Powder Production by Reducing Electrochemically Dissolved Niobium Ions in Molten Salt,” J. Alloy Compd., 454 (1-2) (2008) pp.185-193. DOI: 10.1016/j.jallcom.2006.12.121

[25] Japanese Industrial Standards Committee (JISC), "Fixed Capacitors for Use in Electronic Equipment,” JIS C5101-1, 1998.

[26] Japan Electronics and Information Technology Industries Association (JEITA), “Testing Method of Sintered Body for Tantalum Electrolytic Condenser,” JEITA standards RC-2361A.

[27] B. M. Gatehouse and A. D. Wadsley, "The Crystal Structure of the High Temperature Form of Niobium Pentoxide," Acta Crystallogr., 17 (1964) pp. 1545-1554. DOI: 10.1107/ 


\section{S0365110X6400384X}

[28] J. L. Waring, R. S. Roth, H. S. Parker, "Temperature-Pressure Phase Relationships in Niobium Pentoxide", J. Res. Natl. Bur. Stand., Sect. A, 77A [6] (1973) pp. 705-711. http://archive.org/details/jresv77An6p705

[29] J. L. Fourquet, M. F. Renou, R. De Pape, H. Theveneau, P. P. Man, O. Lucas, J. Pannetier, " $\mathrm{HNbO}_{3}$ : Structure and NMR Study," Solid State Ionics, 9 and 10 [2] (1983) pp. 1011-1013. DOI : 10.1016/0167-2738(83)90123-6

[30] H. Okamoto, "Desk Handbook, Phase Diagrams for Binary Alloys," ASM International, Materials Park, OH, USA, (2000), p. 597.

[31] W. Kitchen, J. Koenitzer, S. Krause, L. Mann, S. Yuan, T. Izumi, Y. Noguchi, “Tantalum Flakes - Powders for High Reliability Electrolytic Capacitor Applications”, Proc. CARTS USA, 2006 (April 3-6, 2006) 7_1zxb.pdf. 


\section{Table captions}

Table 1 Phase identification of the starting powders by XRD measurements.

Table 2 Impurity concentrations and surface areas of the obtained powders.

Table 3 Density after sintering for $1.2 \mathrm{ks}$ at a fixed temperature.

Table 4 Capacitor electric properties of the samples sintered at $1373 \mathrm{~K}$ and $1473 \mathrm{~K}$. The samples were anodically oxidized at $20 \mathrm{~V}$.

\section{Figure captions}

Fig.1 Schematic illustration of the experimental apparatus.

Fig.2 SEM images of starting materials.

Fig.3 XRD patterns of starting materials.

Fig.4 DTA and TG curves of starting material, Type I. Heating rate was $1 / 12 \mathrm{~K} / \mathrm{s}$ in air.

Fig.5 In-situ XRD patterns at high temperatures.

Fig.6 SEM images of reduced powders.

Fig.7 SEM images of sintered pellets, anodically oxidized at $20 \mathrm{~V}$ (a and c), and at $50 \mathrm{~V}$ (b and d). 
Table 1 Phase identification of the starting powders by XRD measurements.

\begin{tabular}{cc}
\hline Sample & Identified phases \\
\hline Type I & Non-crystalline phase \\
Type II & Non-crystalline phase $+\mathrm{CaO}$ \\
Type III & NA \\
Type IV & NA \\
Type V & $\mathrm{Nb}_{2} \mathrm{O}_{5}\left(\mathrm{P}_{2} \# 72-1121[27]\right)$ \\
& $+\mathrm{Nb}_{2} \mathrm{O}_{5}\left(\mathrm{P}_{\text {bam }} \# 27-1003[28]\right)$ \\
\hline
\end{tabular}

\# ICDD-JCPDS card number $[27,28]$. 
Table 2 Impurity concentrations and surface area of the obtained powder.

\begin{tabular}{cccccc}
\hline \multirow{2}{*}{ Sample } & \multicolumn{4}{c}{ Impurity (mass ppm) } & \multirow{2}{*}{ BET(m²/g) } \\
\cline { 2 - 4 } Type I & 8100 & 800 & 3 & 630 & 2.69 \\
Type II & 11100 & 560 & 18 & 690 & 3.41 \\
Type III & 6500 & 430 & 30 & 2860 & N/A \\
Type IV & 10060 & 590 & 40 & 1352 & 1.75 \\
Type V & 8070 & 1430 & 56 & 1550 & 1.47 \\
\hline
\end{tabular}


Table 3 Density after sintering for $1.2 \mathrm{ks}$ at a fixed temperature.

\begin{tabular}{ccccccccc}
\hline & $\begin{array}{c}\text { Density of } \\
\text { Reduced } \\
\text { powder }\end{array}$ & \multicolumn{3}{c}{$\begin{array}{c}\text { Density after sintering, Ds } \\
\left(\mathrm{Mg} / \mathrm{m}^{3}\right)\end{array}$} & \multicolumn{5}{c}{ Ds/Dg } \\
\cline { 3 - 8 } & Dg $\left(\mathrm{Mg} / \mathrm{m}^{3}\right)$ & $1273 \mathrm{~K}$ & $1373 \mathrm{~K}$ & $1473 \mathrm{~K}$ & $1273 \mathrm{~K}$ & $1373 \mathrm{~K}$ & $1473 \mathrm{~K}$ \\
\hline Type I & 2.50 & 2.47 & 2.62 & $\mathrm{NA}$ & 0.99 & 1.05 & $\mathrm{NA}$ \\
Type II & 2.50 & - & 2.74 & 3.24 & - & 1.10 & 1.30 \\
Type V & 2.50 & - & 2.80 & 3.68 & - & 1.12 & 1.47 \\
\hline
\end{tabular}


Table 4 Electric properties as capacitor of the samples sintered at $1373 \mathrm{~K}$ and $1473 \mathrm{~K}$. The samples were anodically oxidized at $20 \mathrm{~V}$.

\begin{tabular}{ccccccc}
\hline & $\begin{array}{c}\text { Capacitance, } \\
\mathrm{CV}(\mu \mathrm{FV} / \mathrm{g})\end{array}$ & \multicolumn{2}{c}{$\begin{array}{c}\text { Leak current, } \\
\text { LC }(\mu \mathrm{A} / \mathrm{g})\end{array}$} & \multicolumn{2}{c}{$\begin{array}{c}\text { Phase delay, } \\
\text { tan }(\%)\end{array}$} \\
\hline $\begin{array}{c}\text { Sintering } \\
\text { temperature }\end{array}$ & $1373 \mathrm{~K}$ & $1473 \mathrm{~K}$ & $1373 \mathrm{~K}$ & $1473 \mathrm{~K}$ & $1373 \mathrm{~K}$ & $1473 \mathrm{~K}$ \\
\hline Type I & 108000 & $\mathrm{NA}$ & 800 & $\mathrm{NA}$ & 98 & $\mathrm{NA}$ \\
Type II & 120000 & 81100 & 703 & 656 & 86 & 32 \\
Type V & 99800 & 68700 & 254 & 132 & 79 & 66 \\
Type V * & NA & 72600 & NA & 656 & NA & 32 \\
\hline
\end{tabular}

* The sample was anodically oxidized at $50 \mathrm{~V}$. 


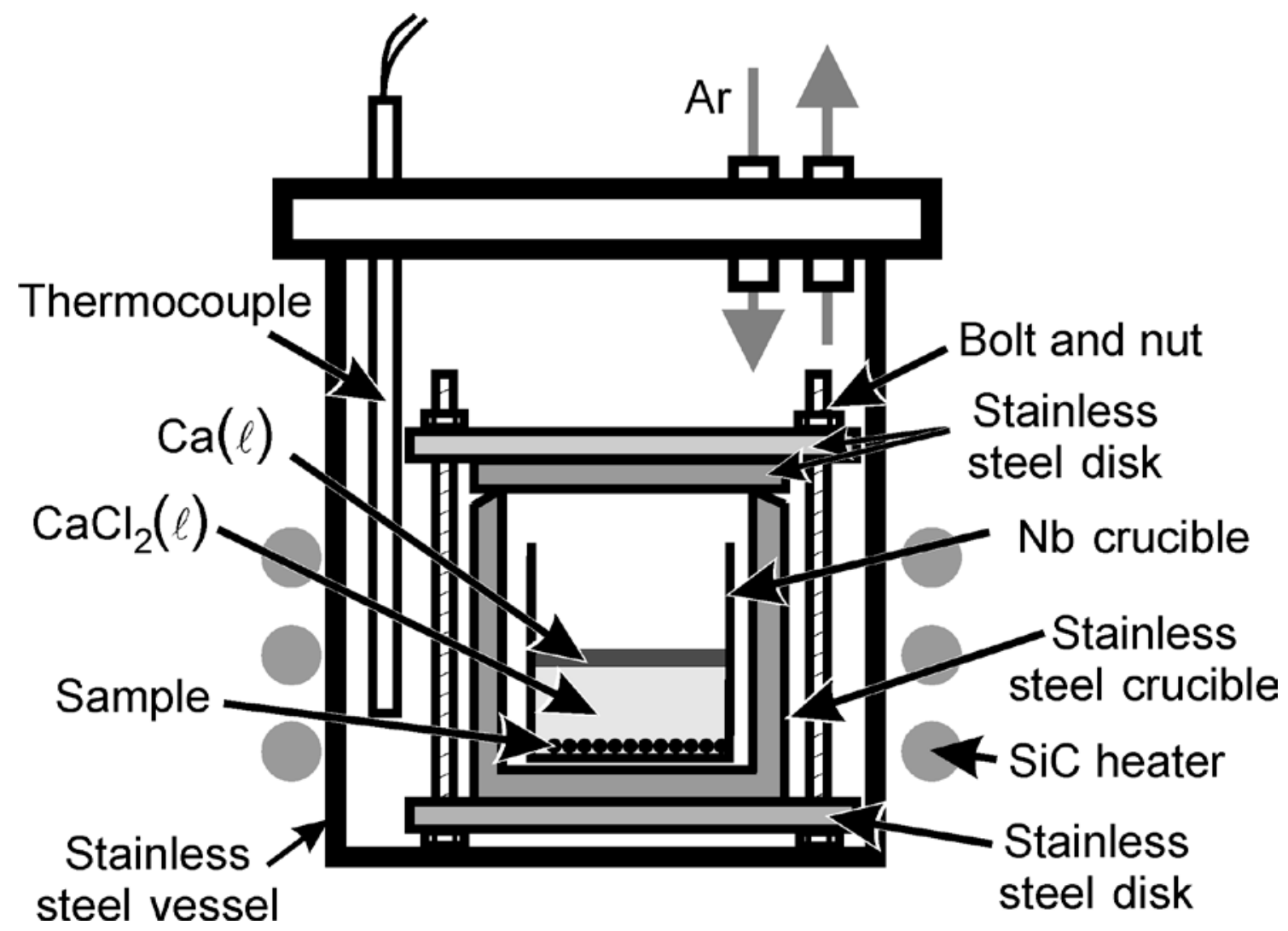

Fig.1 Schematic illustration of the experimental apparatus. 


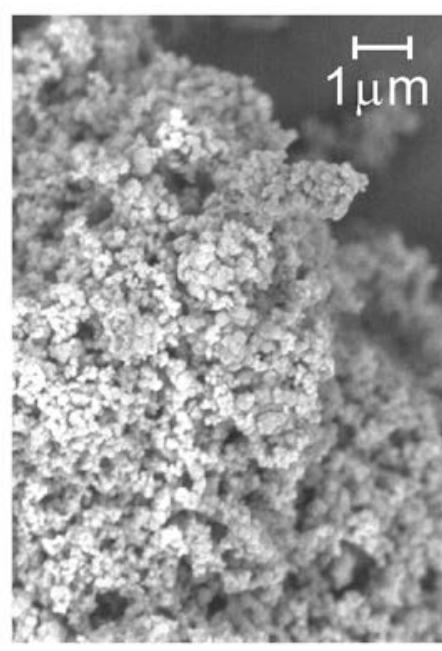

(a) Type I

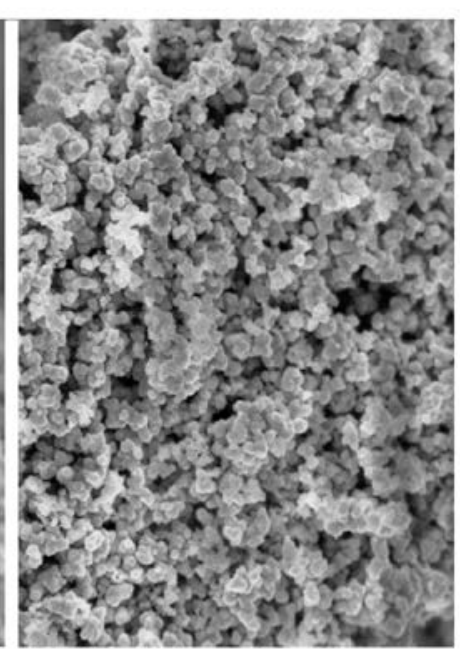

(b) Type II

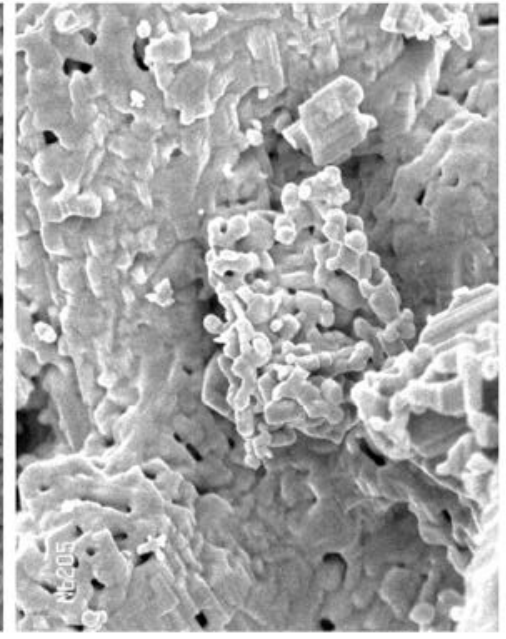

(c) Type V

Fig.2 SEM images of starting materials. 


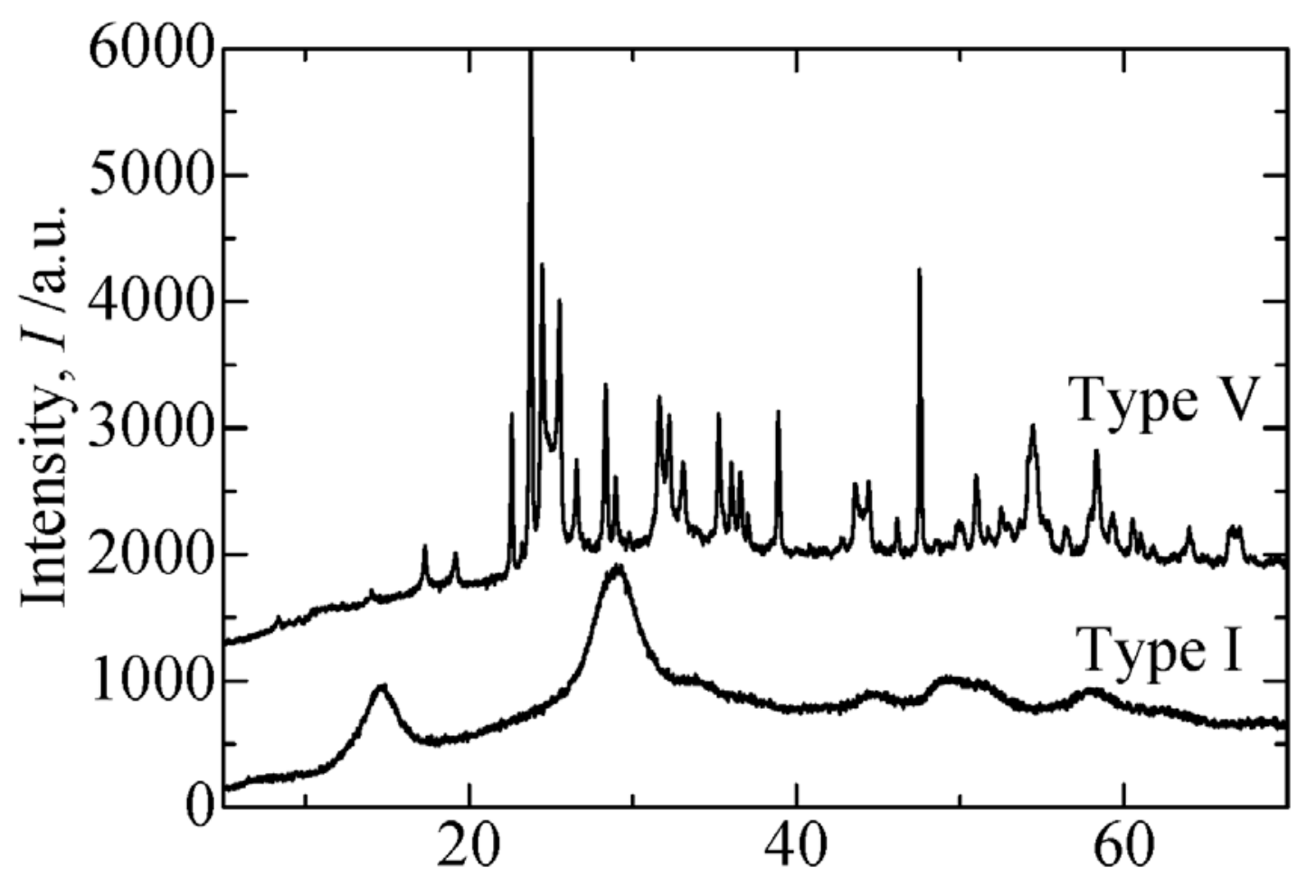

Diffracted angle, $2 \theta /$ deg. $(\mathrm{Cu} K \alpha)$

Fig.3 XRD patterns of starting materials. 


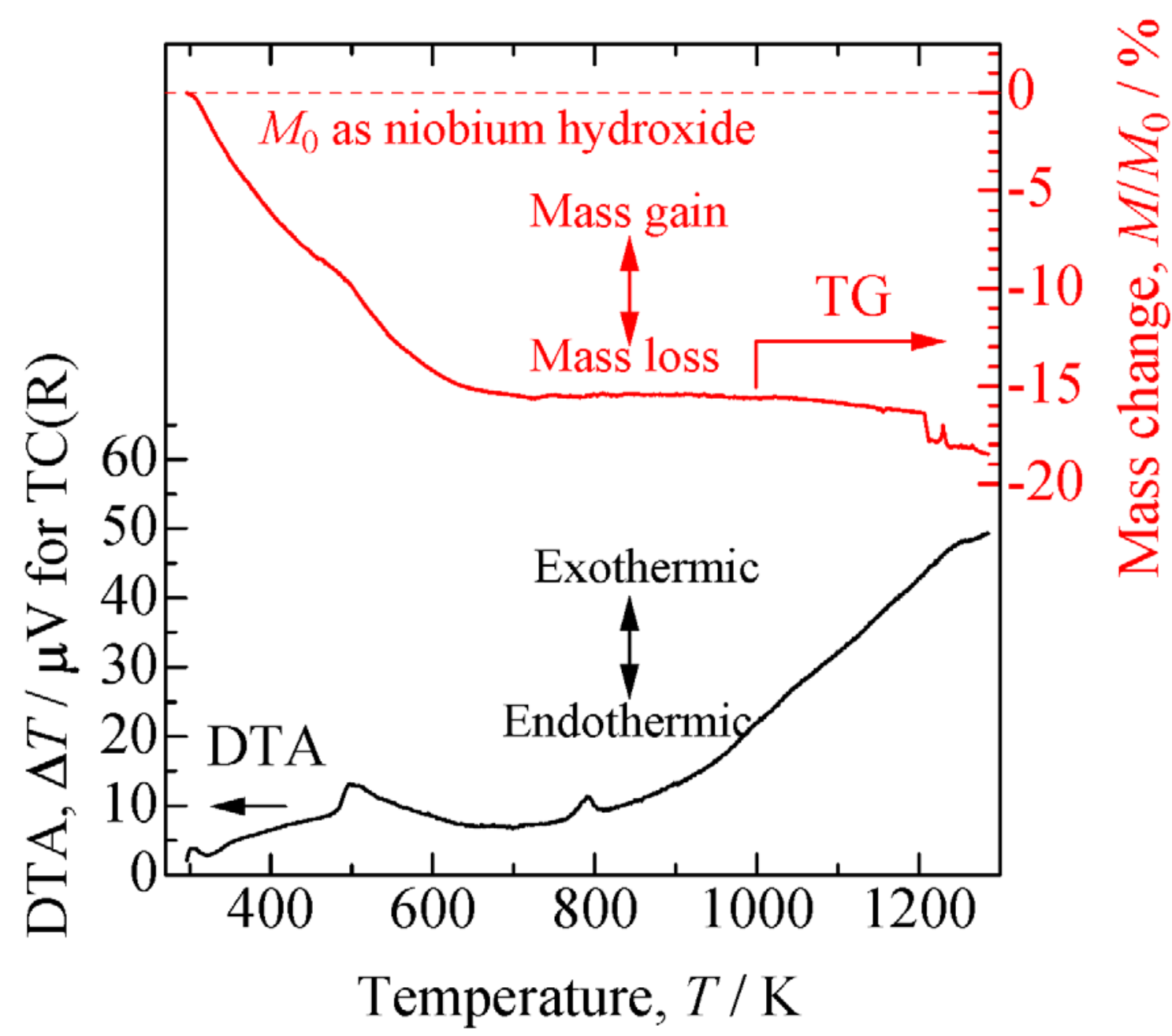

Fig.4 DTA and TG curves of starting material, Type I. Heating rate was $1 / 12 \mathrm{~K} / \mathrm{s}$ in air. 


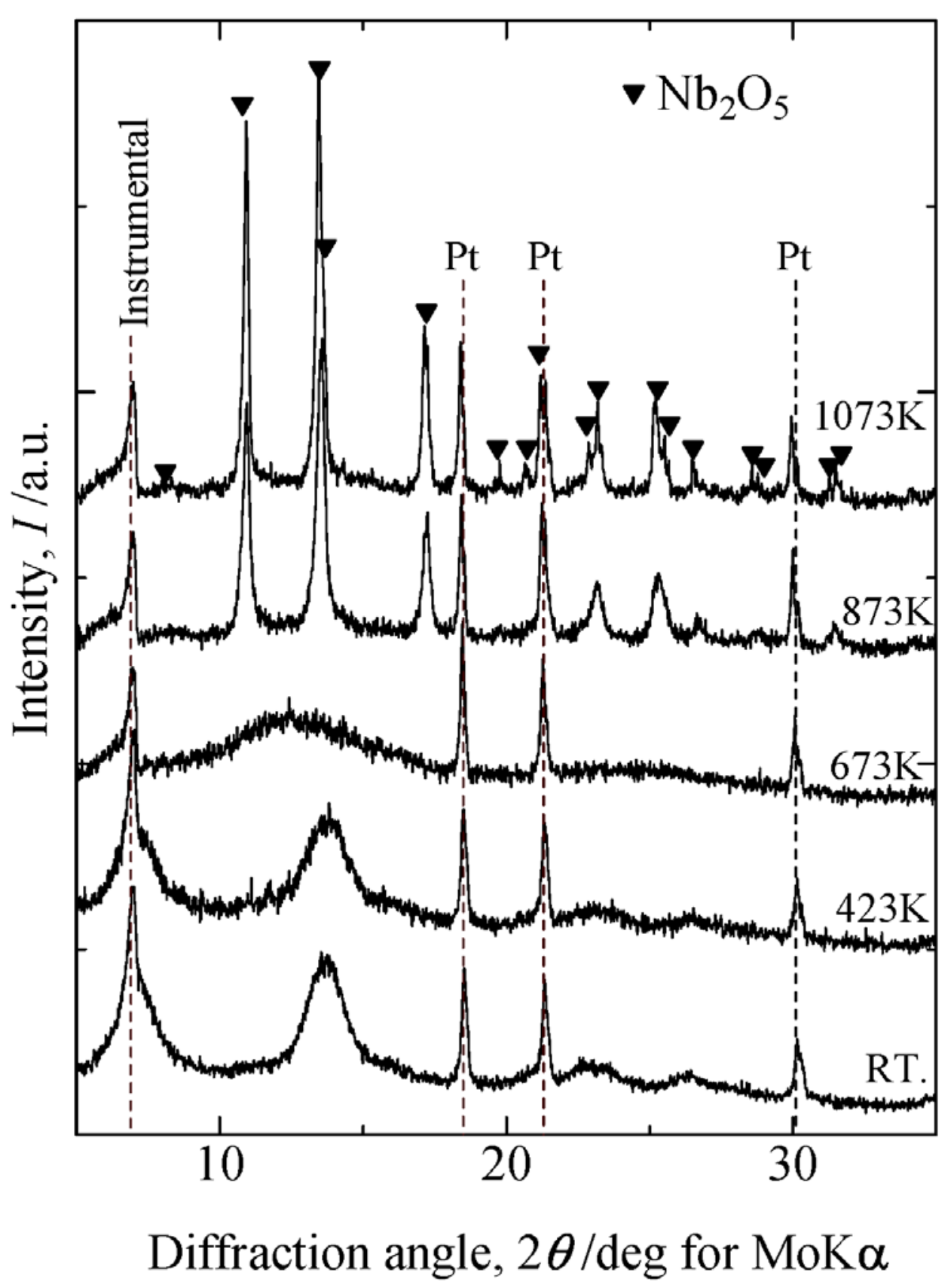

Fig.5 In-situ XRD patterns at high temperatures. 


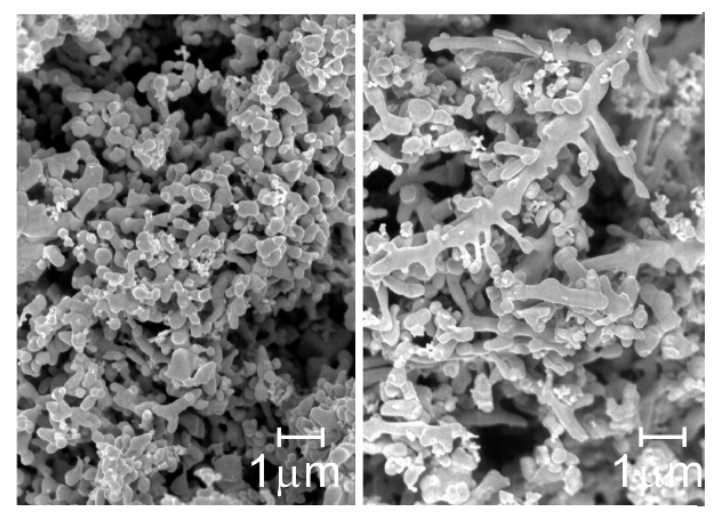

(a)Type I

(b)Type II
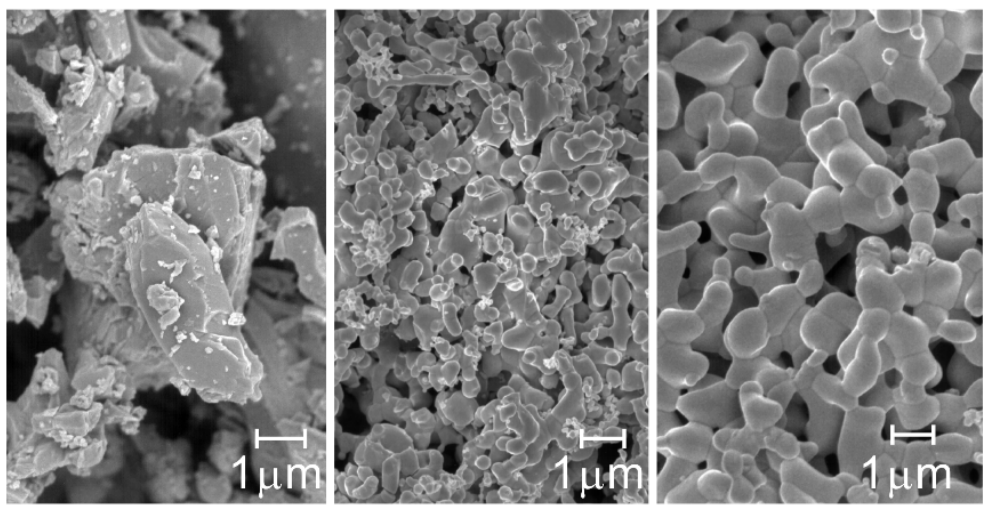

(c) Type III

(d) Type IV

(e)Type V

Fig.6 SEM images of reduced powders. 

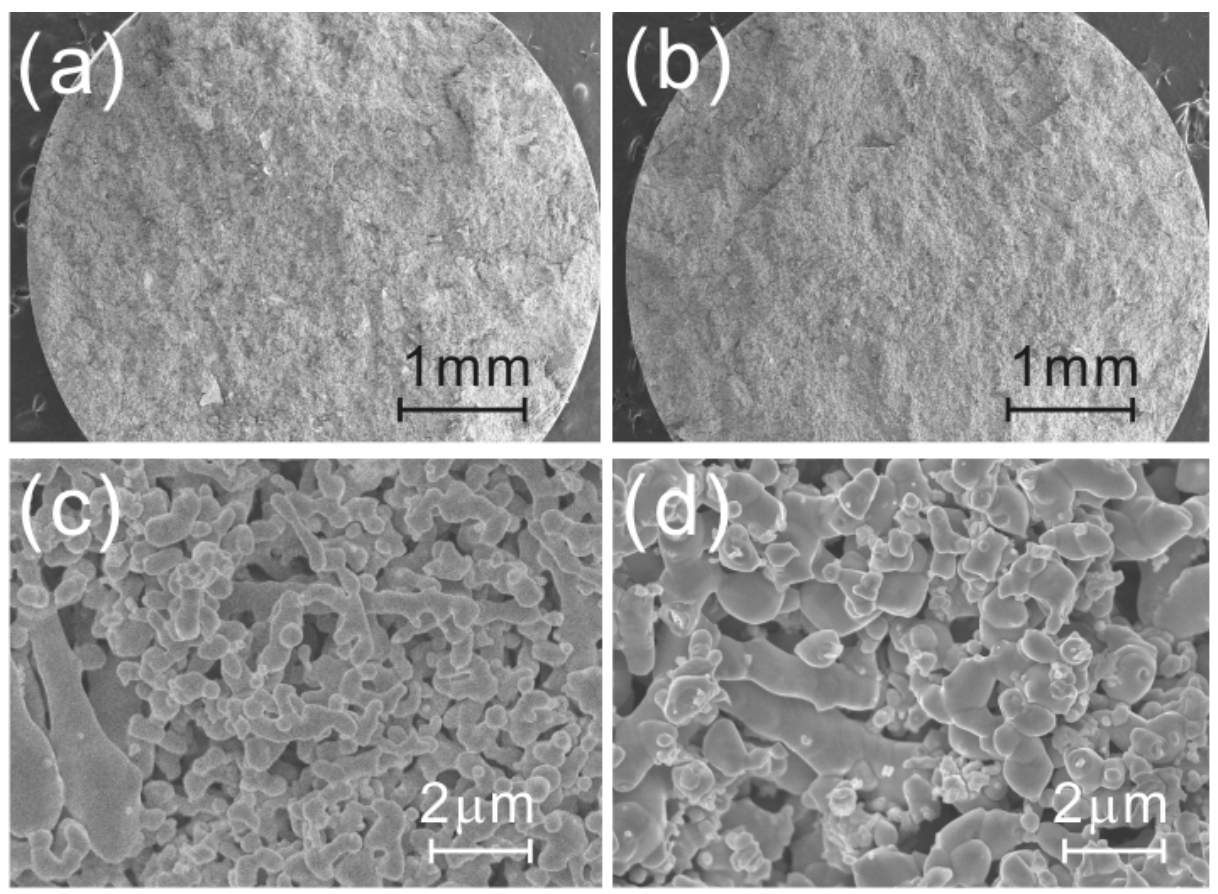

Fig.7 SEM images of sintered pellets, anodically oxidized at $20 \mathrm{~V}$ (a and c), and at $50 \mathrm{~V}$ (b and d). 